Bull. Mater. Sci., Vol. 4, No. 3, May 1982, pp. 289-295. (C) Printed in India

\title{
Potential new experiments on fabrication of cast particulate composites in space
}

\author{
P K ROHATGI, $M$ K SURAPPA and M R MADHAVA \\ Regional Research Laboratory, Trivandrum 695 019, India \\ MS received 4 February 1980 ; revised 10 January 1981
}

\begin{abstract}
Recent developments in fabrication of cast metal ceramic particle compo: sites by liquid metallurgy techniques are outlined. Difficulties encountered in preparing cast composites in the ground environment (including non-uniform distribution and agglomeration of dispersed particles and relatively poor bonding between dispersoids and matrix) and how these can be overcome in a microgravity environment have been discussed. This paper also reviews experiments performed by various space agencies including NASA and ESA on fabrication of composites in space. Some new experiments concerning fabrication of cast composites like dispersion of submicron ceramic particles in molten metals, preparation of cermets with very large volume fractions of ceramic particles and dispersion of flake-type ceramic particles to achieve grain refinement have been proposed.
\end{abstract}

Keywords. Submicron particle ; flake type particle ; powder metallurgy ; dispersion strengthened and particulate composites; wetting; liquid metallurgy technique ; space environment ; grain refinement.

\section{Introduction}

There are three classes of composite materials as distinguished by their microstructures. In each class an elemental or alloy matrix has a second phase distributed in it.

(i) Dispersion strengthened composites

$$
\left(r=0.01 \text { to } 0.1 \mu \mathrm{m} ; V_{1} 1 \text { to } 15 \%\right) \text {, }
$$

(ii) Particulate composites

$$
(r=1 \text { to } 200 \mu \mathrm{m} ; V, 25 \text { to } 85 \% \text { ) and }
$$

(iii) Fibre reinforced composites

$$
(L / d>50 ; V, 40 \text { to } 70 \%) \text {. }
$$

Among the particulate compasites there are metal-matrix ceramic particle composites such as metal-graphite, metal-oxide and metal-mica (named as METCERPS) with low volume fraction dispersoids $(<10 \%)$. These composites passess good properties like low coefficient of friction, improved seizure and wear resistances (adhesive and abrasive wear), improved machinability and high damping cap acity. 
However, dispersion-hardened composites with submicron particle dispersions are known mainly for their superior creep properties at high temperatures.

So far, these metal-ceramic composites (particle and dispersion-hardened) were generally made by powder metallurgical methods. Recently attempts have been made to produce these composites by direct casting route. This technique has many advantages compared to powder metallurgy methods.

In this paper we summarise (a) work on the preparation of cast METCERPS composites and their properties; (b) some of the difficulties encountered in preparing these cast composites in the ground; (c) work done so far by various space agencies to fabricate particle and dispersion-hardened compasites in outer space. Some new experiments on fabrication of cast composites that could be performed in outer space have also been listed.

\subsection{Metal-ceramic particle composites by liquid metallurgy techniques}

Liquid metallurgy technique consists of introduction and dispersion of ceramic particles in molten metal/alloys and solidifying the resultant composite melts in suitable moulds. Introduction of ceramic particles could be accomplished either by (a) mechanical stirring (Badia 1971), (b) gas injection process (Badia and Rohatgi 1969a), (c) pellet technique (Pai and Rohatgi 1978) or (d) injecting powders into a stream of molten metal entering the mold (Rohatgi 1969).

However, generally most ceramic particles are not wetted by liquid metals and under such circumstances, even if the particles are introduced by some means they have a tendency to get separated from the melt. One approach to overcome the wetting problem was to coat the ceramic particles with metal coatings like copper (Pai and Rahatgi 1975) and nickel (Badia and Rohatgi 1969a) before introducing the partioles in the melts. Another approach to improve the wetting is to add anions of refractory particles (Herald and Scruggs 1969) to the melt or/and an element like magnesium (Pai et al 1976; Gorbunov et al 1974) to the melt which will react with the ceramic particles or to add uncoated and untreated ceramic particles to a vigorously agitated, partially solidified slurry of the alloy (Flemings et al 1974).

Recently a more simple and direct method in which uncoated but suitably. treated ceramic particles are introduced into alloy melts has been developed (Surappa 1979; Krishnan 1980). Using this process, ceramio particles such as graphite (Krishnan 1980), alumina (Surappa 1979), mica (Deonath et al 1980), silica (Rohatgi et al 1979), silicon carbide (Surappa 1979), clay (Surappa 1979), shell char (Murali et al 1979) and zircon (Banerjee et al 1979) particles have been dispersed in molten aluminium and its alloys and corresponding cast aluminium composites have been made. Aluminium and its alloys have been used as matrix material in most of our work. However, some wark has alsa been done with other matrix materials like magnesium (Rohatgi 1969), copper (Suwa et al 1977), zinc (Badia 1971), steel (Hasegawa ana Takeshia 1978) and tin (Sartor 1974).

\subsection{Properties of metal-ceramic particle composites}

The physical, mechanical ana tribological properties of cast metal-ceramic particle composites made on the ground at $1 \mathrm{~g}$ have been studied in detail. It has been reported that graphite particle additions to aluminium and its alloys lead to 
improved damping capacity and machinability (Rohatgi et al 1976). Addition of a minimum of $1.8 \%$ graphite to $\mathrm{Al}-12 \mathrm{Si}$ alloy enables its bearings to run under boundary lubrication without galling (Badia and Rohatgi 1969b) and results in decreased wear (Pai et al 1974). A 5\% reduction in specific fuel consumption has been reported (Krishnan et al 1979) using aluminium-graphite pistons in IC engines. A similar reduction in fuel consumption in IC engines using cylinder liners of aluminium graphite has been reported (Bruni and Ignera 1978).

\section{Preparation of cast composites on ground}

Despite the successes achieved in preparing a variety of cast composites by liquid metallurgy techniques several difficulties, some of which are listed below, need to be overcome.

(i) Introducing the as-received ceramic particles into molten alloys without resorting to ultrasonics, additions of surface-active elcments, metal coatings or pre-heat treatment of particles and/or agitation of the bath.

(ii) Introducing submicron particles to praduce dispersion-strengthencd composites.

(iii) Eliminating or minimising gravity-induced floatation or sedimentation of dispersoids especially in slowly cooled castings.

(iv) Obtaining perfectly homogeneous distribution of ceramic particles on macro and microscale in castings.

(v) Getting grain refinement due to the dispersion of these particles.

(vi) Getting the particles entrapped by the freezing interfaces (this results in the particles being present only in the inter-dendrite regions than within the dendrites).

(vii) Obtaining gaod bonding between the particles and the matrix.

\subsection{Space environment in cast composites}

The low gravity $\left(10^{-4}\right.$ to $\left.10^{-5} \mathrm{~g}\right)$ and high vacuum conditions prevailing in space would help overcome many of the difficulties describcd earlier since the absence of gravity would lead to marked reduction in (a) convection phenomena and associated thermal fluctuations, and (b) flotation or sedimentation rates of secand phase particles. Due to considerable reduction in (a) and (b) a stable and homogeneous mixture cf liquid metal and ceramic particles can be obtained. Hence, the distribution of second phase particles in composites (particle and dispersion hardened) prepared in space is expected to be uniform. Surface characteristics of some of the ceramic particles could be different in space, especially if particles are exposed to elevated temperatures in ultrahigh vacuum of space for long periods. This could bring about a significant impravement in wetting between molten metals and refractory particles and this would help in (a) strong cohesian between particles and the matrix; (b) grain refinement due ta presence of dispersed particles; (c) preventing the formation of aggregates and agglomerates; (d) impraved physical and mechanical properties. 


\section{Fabrication of particle and dispersion-hardened composites in space}

Experiments to prepare composites in space have been canducted by many countries and the results appear meaningful. However, in certain cases the results were unexpected and inoonclusive, perhaps due to the improper and inadequate design of experiments.

\subsection{Preparation of $\mathrm{Mg}-\mathrm{ThO}_{2}$ composites by casting}

These experiments were conducted on sounding rockets (SPAR) during a free fall in SPAR I and II flights (Ang and Raymond 1977).

The SPAR I experiment consisted of heating the composite sample containing $2.4 \%$ vol $\mathrm{ThO}_{2}$ particles $(0.8 \mu \mathrm{m})$ in a matrix of $\mathrm{Mg}(75 \mu \mathrm{m})$ which was already made by PM route on the ground. The sample was held for $190 \mathrm{sec}$ at a temperature above $800^{\circ} \mathrm{C}$ and allowed to cool slowly. As compared with ingots made on earth, it was found that the sample processcd in space was relatively more sound and devoid of gas vaids and shrinkage cavities. However, even under space conditions, the distribution of $\mathrm{ThO}_{2}$ particles was not uniform and there were regions which were free from $\mathrm{ThO}_{2}$ particles.

In SPAR II experiment the production of $\mathrm{ThO}_{2}$ dispersions were based on the following reaction:

$$
(2 \mathrm{MgO})_{S}+[\mathrm{Th}]_{L}=\left(\mathrm{ThO}_{2}\right)_{S}+[2 \mathrm{Mg}]_{L} \text {. }
$$

Composite sample consisting of 87.6 wt $\% \mathrm{Mg}(75 \mu \mathrm{m}), 9.2 \mathrm{wt} \% \mathrm{Th}(0.8 \mu \mathrm{m})$ and 3.2 wt $\% \mathrm{MgO}(0.8 \mu \mathrm{m})$ was madz by hot pressing at $250^{\circ} \mathrm{C}$ at earth gravity. In space the sample was heatcd to temperature of $800-950^{\circ} \mathrm{C}$ and maintained for $180 \mathrm{sec}$ followed by rapid quenching. Both the castings made in space and on the ground had little porosity and contained dispersion of $\mathrm{ThO}_{2}$ particles. The size of $\mathrm{ThO}_{2}$ particles in both samples was the same $(0.6 \mu \mathrm{m})$ indicating the absence of agglomeration. $\mathrm{H}_{0}$ wever, the distribution of $\mathrm{ThO}_{2}$ in the spaceprocessed sample was more uniform and the Brinell microbardness of the sample was $31 \pm 3$ whereas that processed in space was only $21 \pm 7$.

\subsection{Experiments on processing of $\mathrm{Be}-\mathrm{BeO}$}

This is one of the most carefully planned experiments and the results are conclusive (Wo::ch et al 1978), although the objective of grain refinement was not ach cved. These experiments were performed in SPAR III flight to prepare cast beryllium having very fine grain structure and improved propertias. The grain refiner tried was $\mathrm{BcO}$. Beryllium alloy containing 1.5 wt $\mathrm{BeO}$ was melted using NASA electromagnetic containerless pracessing payload (ECPP) and re-solidified. The specimen of diameter $0.922 \mathrm{~cm}$ was madz by powder metallurgy (PM) method hot isostatic pressing (HIP). Another specimen from the same billet was melted and resolidified at earth gravity for comparison. More agglomeration and segregation of $\mathrm{BeO}$ particles was found in the specimen prepared on the ground, whereas the distribution of oxide particles was much more uniform in the specimen made in space. However, despite the uniform despersion of BeO particles in the space-processed samples the cast structure of beryllium matrix was not refined. One of the reasons for agglomeration of $\mathrm{BcO}$ particles in groundprocessed specimen is poor wettability between $\mathrm{BeO}$ and molten Be. Results 
indicate that microgravity environment does not totally eliminate agglomeration but only lengthens the time for the onset of agglomeration. The agglomeration time in space is lengthened due to reduction in particle collisions, velocity gradient in the melts and reduced velocity of Stokes flotation. Other factors like poor wettability, surface tension driven convection and electromagnetic stirring caused agglomerates. Absence of grain refinement in the casting despite good dispersion of $\mathrm{BeO}$ has bien attributed to the spheroidal shape of BeO particles, since normal grain refining agents are generally angular or flake type.

\section{3. $A g \rightarrow S i C$ composites}

These experiments were performed on Skylab (Takahiashi 1977) to obtain whiskerstrengthened composites by dispersing SiC whiskets in silver. Results show that the dispersion of SiC whiskers was more uniform in space-processed sample which showed more uniform hardness, greater ductility and higher strength compared to the specimen prepared at $1 \mathrm{~g}$ on ground.

\subsection{Dispersion of non-wettable particles in InBi alloy}

Attempts were made during Apollo-14 flight to incorporate nonwettable particles like tungsten in InBi alloy melts. Results indicate (Yates 1972) that on the ground the tungsten particles were rejected by the melt but it was not so in space.

\subsection{Al-Pb bearing alloy (TEXUS-1, Dec. 1977)}

This experiment was designed to obtain cast $\mathrm{Al}-\mathrm{Pb}$ alloy containing uniform and fine dispersions of lead particles in the matrix of aluminium (Hodes and Steg 1978). Sisch composites are difficult to process on ground due to their large density differences. Initially $\mathrm{Al}-8 \%, \mathrm{~Pb}-3.5 \%, \mathrm{Si}-1.5 \%, \mathrm{Cu}-1 \% \mathrm{Sn}$ alloy was prepared on the ground by PM. The specimen was heated to $1100^{\circ} \mathrm{C}$ in space and allowed to resolidify. The dispersion characteristics of $\mathrm{Pb}$ in $\mathrm{Al}$ were the same both in flight and ground specimens. This has been attributed to the presence of oxide layers on $\mathrm{Pb}$ particles in both specimens preventing fragmentation of lead droplets in the space environment.

\section{Potential experiments on compasites in space}

In all the previous experiments performed in space, the starting material was a composite prepared by powder metallurgy method on the ground. In the case of a compasite so prepared and remelted in space there may not be much difference in the surface characteristics of dispersed phases in PM composite, and in the composite processed in space, since the dispersed particles were not exposed to high vacuum environment prevailing in space. The formation of cast composites will be much easier if the dispersoids are exposed to elevated temperature in space vacuum.

\subsection{Dispersion of graphite, coconut shell char and zircon particles in molten aluminium}

Attempts should be made to disperse $3 \mathrm{wt} \%$ graphite, $\gamma-\mathrm{Al}_{2} \mathrm{O}_{3}$, coconut shell char and zircon particles $(100 \mu \mathrm{m}$ size) in molten aluminium to prepare cast compo- 
sites through liquid metallurgy route in space. A suitable quantity of aluminium should be melted and its temperature raised to $720^{\circ} \mathrm{C}$. The required quantity of graphite or $\mathrm{Al}_{2} \mathrm{O}_{3}$ or shell char or $\mathrm{Zr} \mathrm{SiO}{ }_{4}$ particles $(100 \mu \mathrm{m})$, previously beated to $900^{\circ} \mathrm{C}$ for $2 \mathrm{hr}$ in space, should be added to the surface of molten aluminium. If necessary a mechanical stirrer could be employed to aid dispersion. Molten Al containing suspended particles could be allowed to solidify in moulds identical to those used in the ground. It would be interesting to examine the distribution of these particles especially to measure the interparticle distance in resulting composites, and compare the results with composites processed at $1 \mathrm{~g}$. It would be instructive to examine the fracture surfaces of space-processed composites to determine if in proved bonding is obtained between the metal matrix and ceramic particles.

\subsection{Dispersion strengthened cast $\mathrm{Al}-\mathrm{Al}_{2} \mathrm{O}_{3}$ and cast $\mathrm{Al}$-graphite composites}

Experiments mentioned earlier (\$3.1) could be repeated with $0.01 \mu \mathrm{m}$ size $\mathrm{Al}_{2} \mathrm{O}_{3}$ and graphite. It would be interesting to see whether the initial submicron sizcs of dispersed particles is retained in the castings and if these particles lead to dispersion strengthening.

\subsection{Cast cermets}

Experiments mentioned in $\$ 3.1$ should be repeated with $60-98$ vol \% graphite, zircon, $\mathrm{Al}_{2} \mathrm{O}_{3}$ particle of $100 \mu \mathrm{m}$ size to prepare cermets containing very high volume percentage of ceramic phase. It has not bcen possible to prepare these composites at $1 \mathrm{~g}$ by the casting technique.

\subsection{Dispersion of submicron size flake shaped $\mathrm{a}^{-\mathrm{Al}_{2} \mathrm{O}_{3}}$}

This experiment is conducted to obtain dispersion hardening and grain refinement in aluminium by dispersing flake-shaped and submicron size $a-\mathrm{Al}_{2} \mathrm{O}_{3}$ (and passibly other oxides) particles in malten aluminium and casting the melts. $a-\mathrm{Al}_{2} \mathrm{O}_{3}$ could act as grain refiner since it has the same crystal structure as aluminium (cubic) and there is a hypothesis that grain refining efficacy of flake-shaped particles is higher compared to granular particles.

\subsection{Interaction between moving solid-liquid interface and dispersed particle during solidification}

Pevious experiments on this could be repeated with a slight modification. In the modified set-up the interaction between moving solid-liquid interface and single particle should be studied instead of multiparticle system. This would eliminate the effects due to the crowding of particles. Experiments should alsa be conducted in space on the unidirectional solidification of cast Al-1\% graphite $(40 \mu \mathrm{m})$ particle composite to study the interaction of moving solid-liquid interface, and dispersed graphite particles. On earth the major difficulty in conducting such experiment is flotation of graphite particles due to buoyancy effect. 


\section{References}

Ang C Y and Raymond L 1971 AlAA 15th Aerospace Sciences Meeting, Los Angeles, California, Jan. 1977, Paper No. 77-196

Badia F A 1971 AFS Trans. 79347

Badia F A and Rohatgi P K 1969a AFS Trans. 77402

Badia F A and Rohatgi P K 1969b SAE Trans. 761200

Banerjee A, Surappa M K and Rohatgi P K Oct. 1979 Paper presented at National Seminar on Aluminium Metallurgy held in Bangalore

Brun and Ignera I 1978 Mech. E. 29

Deonath Bhat R T and Rohatgi P K 1980 J. Mater. Sci. 151241

Flemings M C, Mehrabian R and Rieck R G 1974 Metall. Trans. 51899

Gorbunov V G, Parshin U D and Panin V V 1974 Russian Casting production p. 348

Hasegawa M and Takeshia T 1978 Metall. Trans. B9 383

Herald C D and Scruggs D M 1969 Method of producing dispersion strengthened metals, U S Patent No. $3,468,658$

Hodes and Steg M 1978 Final Repart on TEXUS-1 DFULR-BPT

Krishnan B P 1980 Studies on the preparation of cast aluminium alloy-graphite particle composites and their performance in I. C. engine application Ph.D. Thesis, Indian Institute of Science, Bangalore

Krishnan B P, Raman S and Rohatgi P K 1979 Proceedings of International Conference on Wear, Michigan, USA.

Murali T P, Sekhar S, Surappa M K and Rohatgi P K 1979 Paper presented at National Seminar on Aluminium Metallurgy held at Bangalore

Pai B C and Rohatgi P K 1978 J. Mater. Sci. 13329

Pai B C, Ray S, Prabhakar K V and Rohatgi P K 1976 Mater. Sci. Engg. 2431

Pai B C and Rohatgi P K 1975 Mater. Sci. Engg. 21161

Pai B C, Rohatgi P K and Venkatesh S 1974 Wear 30177

Rohatgi P K 1969 Unpublished results

Rohatgi P K, Pai B C and Panda P C 1979 J. Mater. Sci. 142277

Rohatgi P K, Murali N, Shetty H R and Chandrashekar R 1976 Mater. Sci. Engg. 26115

Sartor B 1974 Metall. 22771

Surappa M K 1979 Preparation and properties of cast aluminium alloy ceramic particles composites Ph.D. Thesis, Indian Institute of Science, Bangalore

Suwa M, Komure K and Soeno K 1977 Nippon Kinzokee Grukkaishi 41511

Takahiashi S Jan. 1977 AIAI 15th Aerospace Sciences Meeting Los Angeles, California, Paper No. 77-195

Wouch G, Frost R T, Pinto N P, Keith G H and Lord A E 1978 Nature (London) 274235

Yates I C March 1972 Apollo 14 Composite casting Demonstration Final Report, NASA TMS-64641 